\title{
VITAMIN D IN THE COVID-19 PREVENTION AND TREATMENT: EMERGING EVIDENCE
}

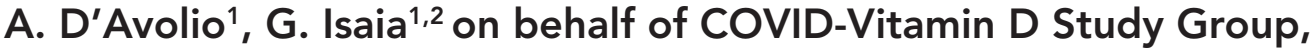 Accademia di Medicina di Torino}

${ }^{1}$ Department of Medical Sciences, University of Turin, Turin, Italy

${ }^{2}$ Accademia di Medicina di Torino, Turin, Italy

Antonio D'Avolio and Giancarlo Isaia contributed equally to this work.

E-mail: antonio.davolio@unito.it

Doi: $10.36118 /$ pharmadvances.2021.01

\section{SUMMARY}

The significantly higher incidence of COVID-19 on mortality and morbidity observed in the northern Italian regions as compared to the southern ones, could be partly explained by geographic variations of the prevalence of vitamin D deficiency. The present opinion paper discusses this hypothesis.

The immunomodulatory effects of vitamin $D$ have been widely established and its benefits on viral and bacterial replication have been attributed to its ability to modulate gene expression by activating the vitamin $D$ receptor in many target cells, including immune cells, and by promoting the expression of antimicrobial peptides such as cathelicidins and beta-defensins, which are also endowed with antiviral and immunomodulatory properties.

Recently, following the onset of the COVID-19 pandemic situation, many studies have shown a high prevalence of very low levels of vitamin $D$ in patients with severe manifestations of the disease, and that high dose vitamin $D$ administration appeared able to favourably modify the evolution of the infection. Although these studies, mainly based on crosssectional analyses and small-scale randomized clinical studies, could not provide a definitive proof of a cause-effect relationship, it is possible to suggest that hypovitaminosis D might be considered "guilty by association" as one of the factors able to worsen the pandemic spread and its clinical impact.

\section{Key words}

Vitamin D; Covid-19; SARS-CoV-2; supplementation, therapy.

\section{INTRODUCTION}

Last year has shown that COVID-19 pandemic has specific characteristics, but scientific research, mostly geared towards development of specific antibodies and vaccines to contrast the virus, has not provided enough knowledge about other alternative tools to fight the disease. Little is known about the pathophysiological characteristics of the dis-

\section{Impact statement}

A rational use of Vitamin $D$ is required in order to guarantee a correct immunomodulation in fragile population.

ease, the mechanisms that favour the infection of the human species or about the molecular targets to develop pharmacological treatment. Due to these unaddressed issues, new protective strategies are very hard to propose and validate and therefore, they are currently limited to the undisputable and fundamental measures of physical distance and individual hygiene. 
In Italy, one of the most heavily afflicted European countries, significant differences in mortality and morbidity by COVID-19, have been observed between northern and southern regions, with a greater impact in northern regions, at least during the first wave. Moreover, the disease has proven to be particularly aggressive in older people $(78.4 \%$ of the dead patients aged between 60 and 89 years), notably in nursing home residents (Sars-cov-2 decessi Italia). In the past, the important role of solar radiation, empirically deducted from latitude, was proven in the case of the 1918-1919 pandemic influenza in the USA (1).

For these reasons, hypovitaminosis $D$, mainly due to lack of solar UV radiations and more frequent in aging population and resulted, also for diet, highest during the winter and spring, when $25(\mathrm{OH}) \mathrm{D}$ concentrations $<25$, $<40$, and $<75 \mathrm{nmol} / \mathrm{L}$ were found in $15.5 \%$, $46.6 \%$, and $87.1 \%$ of participants, respectively (2): for these reasons it has been assumed to be one possible additional causal determinant of the pandemic (3). The link between COVID-19 and hypovitaminosis D has also been suggested by the results of our recent ecological-statistical study (4) performed in collaboration with several Italian universities and environmental institutions, in which we examined the spatial distribution of the outbreak in Italy during the first-wave period (February-May 2020); our country is the ideal test area to explore a correlation between the clinical outcomes of the pandemic and the geographical distribution of solar UV irradiance, due to its long extension, ranging from latitudes higher than $46^{\circ} \mathrm{N}$ in Trentino-South Tyrol, to less than $36^{\circ} \mathrm{N}$ in Sicily: it has been assessed the levels of ultraviolet rays (UV) at the Earth's surface and compared it with the number of dead and affected patients. The investigation proved that regional COVID-19 deaths and infections had a very significant correlation with the intensity of solar UV at the Earth's surface measured in each region by satellite and soil detection (5).

\section{RELATIONSHIP BETWEEN VITAMIN D AND COVID-19 PATHOPHYSIOLOGY AND COMPLICATIONS}

A large number of papers recently published have considered the link between COVID-19 and vitamin $D$, both with retrospective investigations (6) and metanalysis (7). In general, the presence of hypovitaminosis $D$ of patients with COVID-19, especially in severe cases (more than $50 \%$ of the cases) (8) and higher associated mortality, with odd ratio of 1.82 (5) and 3.87 (9), has been confirmed. In a study including either asymptomatic or severely ill COVID-19 patients requiring Intensive Care Unit (ICU) admission, and adopting the cut-off concentration level of serum 25-hydroxyvita$\min \mathrm{D}[25(\mathrm{OH}) \mathrm{D}]<30 \mathrm{ng} / \mathrm{ml}$ for define vitamin $\mathrm{D}$ deficiency, its prevalence was $31.86 \%$ and $96.82 \%$ respectively (10).

Although the presence of a "reverse causality" cannot still be ruled out, several pathophysiological mechanisms explaining the possible influence of hypovitaminosis D on COVID-19 have been brought forward (11):

a) it is well known that the active metabolite of vitamin $D$, calcitriol $\left[1,25(\mathrm{OH})_{2} D_{3}\right]$, exerts many different biological effects: its specific receptor (VDR) is present in many tissues as well as white blood cells, where it mediates the immune response (12). Particularly, intracellular synthesis of calcitriol by monocytes/ macrophages promotes the expression of the antimicrobial proteins cathelicidins and beta-defensins, and enhances intracellular killing of endocytosed microbes in innate immunity. Moreover, calcitriol exerts an inhibitory, anti-inflammatory effect, preventing multiple organ damage in adaptive immunity (13). Thus, it suppresses the progression of inflammation by reducing the generation of pro-inflammatory cytokines such as IL-12, IL-2, and interferon gamma (IFN- $\gamma)$, involved in the $\mathrm{T}$ helper type 1 response, and IL-17, involved in the Thelper type 17 response, and accompanying the decrease of acute inflammation mediators such as TNF $\alpha, \mathrm{IL}-6$, and IL-8 $(14,15)$. 
b) Angiotensin II (Ang II) is a natural peptide hormone which play a pivotal role in the renin-angiotensin-aldosterone system and Angiotensin Converting Enzyme 2 (ACE2) directly catalyzes the conversion of Ang II to angiotensin-(1-7), thereby lowering its levels. COVID-19 infection appears to downregulate ACE2, which in turn could lead to excessive accumulation of Ang II which exerts pro-inflammatory properties. High levels of Ang II may cause Acute Respiratory Distress Syndrome (ARDS), myocarditis, or cardiac injury, and, interestlingly, vitamin D supplementation was shown to prevent Ang II accumulation and to decrease its proinflammatory activity by suppressing the release of renin in patients infected with COVID-19 (16).

c) It is also plausible that a reduced availability of 7-dehydrocholesterol - the chemical precursor of vitamin D found in large amounts in keratinocytes - led to a reduction in the levels of its metabolite vitamin $D$ as a consequence of the marked reduction of cholesterol observed in patients with moderate or severe forms of COVID-19 (17).

\section{CLINICAL REPORTS}

Recent clinical contributions provide interesting suggestions for low-cost interventions, and potentially useful to the entire elderly population that in Italy (18) is largely vitamin D deficient, likely due to the lack of vitamin D food fortification.

To build a proposal, we have selected some papers regarding clinical trials, supporting the usefulness of vitamin D administration (mainly cholecalciferol) for both prevention and treatment of COVID-19 patients:

1) in a randomised study of 76 symptomatic COVID-19 patients, the percentage of subjects for whom intensive care unit admission was required was $2 \%$ in the group treated with high-dose calcifediol and $50 \%$ in untreated patients (19).

2) A retrospective study of over 190,000 patients evidenced a significant inverse cor- relation between SARS-CoV-2 positivity rates and circulating levels of vitamin $D(20)$.

3) In 77 elderly subjects hospitalized for COVID-19, the probability of survival estimated was significantly and positively related to the administration of cholecalciferol, taken in the previous year at the dose of 50,000 IU per month, or $80,000 \mathrm{IU}$ for 2-3 months, or $80,000 \mathrm{IU}$ at the time of diagnosis (21).

4) In PCR-positive patients for SARS-CoV-2, vitamin $D$ levels were significantly lower ( $p$ $=0.004)$ than in negative PCR ones (22): these findings were confirmed by other works in terms of increased viral clearance and healing for those with higher blood vitamin D levels.

5) In a clinical trial on 40 asymptomatic or oligosymptomatic patients, disease negativization in $62.5 \%$ of patients treated with high-dose cholecalciferol $(60,000 \mathrm{IU} /$ die for 7 days) as compared to $20.8 \%$ of patients in the control group was observed (23).

\section{COMMENTS}

Based on the results of these and other studies, we can make the following remarks:

1) although further controlled and randomized studies are required, vitamin $D$ appears more effective against COVID-19 (both for negativity rate and for benign evolution of the disease) when administered for preventive purpose, particularly in fragile and institutionalised elderly subjects (24). There is pathophysiologic rationale for exploring the use of vitamin $D$ in this global pandemic, despite supported by early reports from international groups (25).

2) The minimum plasma target level of $25(\mathrm{OH})$ $D$ to be achieved for prevention would be $40 \mathrm{ng} / \mathrm{ml}$ (26). To reach this target value, high cholecalciferol doses - up to 4,000 IU per day, depending on patient baseline plasma $25(\mathrm{OH}) \mathrm{D}$ levels - have to be administered (27).

3) Randomized studies indicate the usefulness of a single bolus administration of 80,000 
IU of cholecalciferol $(21,23)$ or calcifediol $(0.532 \mathrm{mg}$ on the first day, $0.266 \mathrm{mg}$ on the third and seventh days and then once a week) (19) or 60,000 UI of cholecalciferol for seven days with the aim of achieving a serum $25(\mathrm{OH}) \mathrm{D}$ concentration of $50 \mathrm{ng} / \mathrm{ml}$ $(23,25)$.

Despite these and other data, vitamin D supplementation as a prevention strategy against COVID-19 is not widely used because of the lack of randomized placebo-controlled trials. However, unlike other vitamins or supplements, evidence on the usefulness of vitamin $D$ in the settings of prevention and treatment of COVID-19 is gradually emerging. A recent review suggested that vitamin $D$ supplementation might play a role in the prevention and/ or treatment to SARS-CoV-2 infection disease, by modulating the immune response to the virus both in the adult and paediatric population (28). Instead, in UK supplementation of vitamin $D$ to 2.7 million people at risk of COVID-19 (the elderly, the black population or the residents in nursing homes) was recently disposed and defined as a "low-cost, zero-risk, potentially highly effective action" (https:// www.theguardian.com/world/2020/nov/14/ covid-uk-government-requests-guidance-onvitamin-d-use): the subsequent debate led NICE expressed some doubts (www.nice.org. uk/guidance/ng187): in particular NICE state that there is not enough evidence to support taking vitamin $\mathrm{D}$ solely to prevent or treat COVID-19. Nevertheless, the Royal Society of London to state that it "...seems nothing to lose and potentially much to gain".

\section{CONCLUSIONS}

In conclusion, although the usefulness of vitamin $D$ in the prevention and treatment of COVID-19 is not yet fully defined (not even for SARS-CoV-2 variants), we believe that that there is a great need for further research in this field that should be taken into account by the public health Institutions, to possibly promote: a) activation of a consensus conference or/and a randomized and controlled clinical trial on the therapeutic efficacy of vitamin $D$ in symptomatic or oligosymptomatic COVID-19 patients, according to one of the following schedules of vitamin $D$ administration:

- oral cholecalciferol 60,000 IU per day for seven consecutive days;

- single cholecalciferol administration $(80,000 \mathrm{IU})$ in aged patients;

- oral calcifediol $0.532 \mathrm{mg}$ on day 1 and $0.266 \mathrm{mg}$ on days 3 , and 7 once weekly afterwards.

b) Preventive administration of oral cholecalciferol (up to 4,000 IU per day) to subjects at higher risk of contagion and disease severity (frail elderly, obese subjects, health care professionals, close contacts and relatives of infected patients, subject from closed communities), especially during the cold period; it is important noting that in this context vitamin D non-hydroxylated compounds are not associated with significant side effects (29). Anyway, vitamin D supplementation would be helpful to correct vitamin D deficiency - which is also regarded as a global pandemic, especially during the winter months and irrespective of SARS-CoV-2 infection.

c) The organization and promotion of public health campaigns aimed to raise awareness of both positive and negative effects of the solar radiation and also by fostering active measures to increase the individual serum vitamin D levels, either through pharmacological supplementation (carried out under medical supervision) or through the consumption of vitamin-D-rich foods. This is particularly true for the elderly, since: (i) in general, they seldom set themselves to the sun and their skin has a lower efficiency in the synthesis of vitamin $D$ compared to young people (30); (ii), they do not gladly eat food containing vitamin $D$, such as fat cheese, butter, mushroom, some fish; (iii) the assumption of food fortified with vitamin $D$ is not very diffused in Italy. 


\section{CONFLICT OF INTERESTS}

The authors and the members of "COVID-Vitamin D Study Group, Accademia di Medicina di Torino"* declare that they have no conflict of interests to disclose in the specific field covered by this paper.

* D. Agnusdei (Siena), P. M. Allegri (Padua), F. Altruda (Turin), A. Angeli (Turin), P. Arese (Turin), M. Astegiano (Turin), A. Aversa (Catanzaro), M. Barbagallo (Palermo), M. Baroni (Perugia), A. Bargoni (Turin), C. Bertino (Turin), L. Biancone (Turin), A. Biolcati (Novara), E. Bologna (Alba - CN), A. Bosia (Turin), G. M. Bruno (Pavia), C. Bucca (Turin), E. Cacace (Cagliari), R. Caccialanza (Pavia), T. Cammarota (Turin), V. Camozzi (Padua), C. Campagnoli (Turin), M. Campogrande (Turin), M. Caprio (Rome), A. Catalano (Viterbo), R. Cavallo (Turin), P. Cavallo Perin (Turin), C. Ceruti (Turin), A. Cester (Venezia), A. Chiò (Turin), A. Ciampolillo (Bari), A. Cicero (Bologna), C. Cisari (Novara), A. Colao (Napoli), A. Comandone (Turin), L. Cordero di Montezemolo (Turin), F. Crapanzano (Agrigento), S. Cristallini (Perugia), F. D'Ambrosio (Ancona), G. D'Avola (Acireale, CT), C. Del Prete (Lugano, CH), G. De Renzi (Orbassano, Turin), C. de Sanctis (Turin), U. Dianzani (Novara), F. Di Carlo (Turin), O. Di Munno (Pisa), F. Di Salvo (Palermo), F. Di Stefano (Omegna, VB), M. Di Stefano (Turin), L. Dominguez (Palermo), P.P. Donadio (Turin), F. Dotta (Siena), A. Fabbri (Rome), S. Falcone (Rome), R. Fantozzi (Turin), E. Favaro (Turin), R. Ferracini (Genova), E. Ferretti (Rome), M. T. Fierro (Turin), E. Finocchiaro (Turin), S. Flangini (Legnago, VR), C. Foresta (Padua), G. Fornero (Turin), G. Forni (Turin), C. M. Francucci (Ancona), R. Fruttero (Turin), E. Fusaro (Turin), A. Gaetini (Turin), L. Gallelli (Catanzaro), M. Ales- sandra Gardini (Rome), G. Gasparri (Turin), A. Gaudio (Catania), G. Giacchetti (Ancona), S. Gonnelli (Siena), M. Grano (Bari), M. Infante (Rome), G. Isaia (Turin), C. Laurentaci (Matera), G. L. Mauro (Palermo), P. Limone (Turin), R. Liuzza (Monza), S. Livigni (Turin), L. Maffi (Turin), S. Maggi (Padua), M. Maggiorotti (Rome), F. Malavasi (Turin), M. Marangella (Turin), N. Marchionni (Florence), A. Massè (Turin), A. Mattioda (San Maurizio Canavese, Turin), P. Mecocci (Perugia), E. Medico (Turin), S. Migliaccio (Rome), M. Alessandro Minetto (Turin), G. Minisola (Rome), V. Modena (Turin), E. Montanari (Bologna), F. Monzani (Pisa), F. Morabito (Alba, CN), M. Morello (Rome), E. Morini (Messina), R. Mutani (Turin), M. Nano (Turin), F. Orlandi (Turin), V. Ortore (Rome), A. Palma (Melegnano, Milan), L. M. Pernigotti (Turin), A. Piazza (Turin), G. Pietrocola (Pavia), L. Pietrogrande (Milano), G. Poli (Turin), F. Porpiglia (Turin), P. Presbitero (Rozzano, Milan), P. Quaglino (Turin), U. Ramenghi (Turin), Z. Ranieri (Milan), D. Regge (Turin), U. Riba (Turin), G. R. Riccardi (Ancona), G. Ricevuti (Pavia), S. Rindi (Pavia), D. Roccatello (Turin), A. Romeo (Siracusa), V. Ronconi (Jesi, AN), F. Rosina (Turin), C. Ruggiero (Perugia), G. Saglio (Turin), S. Salomone (Palermo), A. Sapino (Turin), L. Sartori (Padua), F. Scarnati (Taverna di Montalto, CS), F. Scaroina (Turin), G. Segoloni (Turin), L. Massimino Sena (Turin), U. Senin (Perugia), M. Sfrappini (Ancona), E. Shahini (Candiolo, Turin), D. Silengo (Turin), A. Silvestri (Cuneo), G. Spera (Rome), P. Stratta (Novara), L. Sutera (Palermo), L. Tafaro (Rome), G. Tanturri (Turin), F. M. Ulivieri (Milan), L. Vaira (Rivoli, Turin), A. Vercelli (Turin), N.Veronese (Palermo), F. Vescini (Udine), R. Vettor (Padua), P. Villaba Fabiano (Frosinone), E. Villari (Turin), E.Viora (Turin), U. Vitolo (Candiolo, Turin).

\section{REFERENCES}

1. Grant WB, Giovannucci E. The possible roles of solar ultraviolet-B radiation and vitamin $D$ in reducing case-fatality rates from the 1918-1919 influenza pandemic

in the United States. Dermato-Endocrinol 2009;4:215-9

2. Hyppönen E, Power C. Hypovitaminosis $D$ in British adults at age $45 \mathrm{y}$ : nationwide 
cohort study of dietary and lifestyle predictors Am J Clin Nutr 2007;85(3):860-8.

3. Isaia GC, Medico E. Associations between hypovitaminosis D and COVID-19: a narrative review. Aging Clin Exp Res 2020 Sep;32(9):1879-81. Doi: 10.1007/s40520020-01650-9.

4. Isaia GC, Diémoz H, Maluta F, et al. Does solar ultraviolet radiation play a role in COVID-19 infection and deaths? An environmental ecological study in Italy Sci. Total Environ $2021 ; 757: 143757$. Doi:10.1016/j.scitotenv.2020.143757.

5. Van Geffen J, Van Weele M, Allaart M, Van Der R. TEMIS UV index and UV dose operational data products, version 2. 2017 Royal Netherlands Meteorological Institute (KNMI). Doi.org/10.21944/temis-uv-oper-v2.

6. Meltzer DO, Best TJ, Zhang H, Vokes T, Arora V, Solway J. Association of Vitamin $D$ status and other clinical characteristics with COVID-19 Test Results. JAMA Netw Open 2020;3(9):e2019722. Doi: 10.1001/ jamanetworkopen.2020.19722.

7. Pereira M, Dantas Damascena A, Galvão Azevedo LM, de Almeida Oliveira T, da Mota Santana J. Vitamin $D$ deficiency aggravates COVID-19: systematic review and meta-analysis. Crit Rev Food Sci Nutr. 2020:19. Doi: 10.1080/10408398.2020.1841090. Epub ahead of print.

8. Infante M, Buoso A, Pieri M, et al. Low Vitamin $D$ status at admission as a risk factor for poor survival in hospitalized patients with COVID-19: an Italian retrospective study JACN, in press.

9. De Smet D, De Smet K, Herroelen P, Gryspeerdt S, Martens GA. Serum 25(OH) $D$ level on hospital admission associated with COVID-19 Stage and Mortality. Am J Clin Pathol 2020: aqaa252. Doi: 10.1093/ ajcp/aqaa252. Epub ahead of print.

10. Jain A, Chaurasia R, Sengar NS, Singh M, Mahor S, Narain S. Analysis of vitamin D level among asymptomatic and critically ill COVID-19 patients and its correlation with inflammatory markers. Sci Rep
2020;10(1):20191. Doi: 10.1038/s41598020-77093-z.

11. Aygun H. Vitamin D can prevent COVID-19 infection-induced multiple organ damage. Naunyn Schmiedebergs Arch Pharmacol 2020;393(7):1157-60. Doi: 10.1007/ s00210-020-01911-4. Epub 2020 May 25.

12. Charoenngam N, Holick MF. Immunologic Effects of Vitamin D on human health and disease. Nutrients 2020;12(7):2097. Doi: 10.3390/nu12072097. PMID: 32679784; PMCID: PMC7400911.

13. Bilezikian JP, Bikle D, Hewison $M$, et al. Mechanisms In Endocrinology: Vitamin $D$ and COVID-19. Eur J Endocrinol 2020;183(5):R133-R147. Doi: 10.1530/EJE20-0665. PMID: 32755992.

14. Grant WB, Lahore $H, M c D o n n e l l ~ S L$, Baggerly $\mathrm{CA}$, French $\mathrm{CB}$, Aliano JL, Bhattoa HP. Evidence that Vitamin D supplementation could reduce risk of influenza and covid-19 infections and deaths. Nutrients 2020;12(4):988. Doi: 10.3390/nu12040988.

15. Fabbri A, Infante $M$, Ricordi C. Editorial - vitamin D status: a key modulator of innate immunity and natural defense from acute viral respiratory infections. Eur Rev Med Pharmacol Sci 2020;24(7):4048-52.

16. Hanff TC, Harhay MO, Brown TS, Cohen JB, Mohareb AM. Is there an association between COVID-19 mortality and the renin-angiotensin system? A call for epidemiologic investigations. Clin Infect Dis 2020;71(15):870-4. Doi: 10.1093/ $\mathrm{cid} / \mathrm{ciaa329}$.

17. Marcello A, Civra A, Milan Bonotto R, et al. The cholesterol metabolite 27-hydroxycholesterol inhibits SARS-CoV-2 and is markedly decreased in COVID-19 patients. Redox Biol. 2020 Sep; 36:101682. Doi: 10.1016/j.redox.2020.101682.

18. Isaia G, Giorgino R, Rini GB, Bevilacqua $M$, Maugeri $D$, Adami S. Prevalence of hypovitaminosis $D$ in elderly women in Italy: clinical consequences and risk factors. Osteoporos Int 2003;14(7):577-82. Doi: 10.1007/s00198-003-1390-7. 
19. Entrenas Castillo M, Entrenas Costa LM, Vaquero Barrios JM, et al. Effect of calcifediol treatment and best available therapy versus best available therapy on intensive care unit admission and mortality among patients hospitalized for COVID-19: A pilot randomized clinical study. J Steroid Biochem Mol Biol 2020;203:105751. Doi: 10.1016/j.jsbmb.2020.105751.

20. Kaufman HW, Niles JK, Kroll MH, Bi C, Holick MF. SARS-CoV-2 positivity rates associated with circulating 25-hydroxyvitamin D levels. PLoS One 2020;15(9):e0239252. Doi: 10.1371/journal.pone.0239252.

21. Annweiler G, Corvaisier M, Gautier J, et al. Vitamin $\mathrm{D}$ supplementation associated to better survival in hospitalized frail elderly COVID-19 patients: The GERIA-COVID Quasi-Experimental Study. Nutrients 2020;12(11):3377. Doi: 10.3390/nu12113377.

22. D'Avolio A, Avataneo V, Manca A, et al. 25-Hydroxyvitamin $D$ concentrations are lower in patients with positive PCR for SARS-CoV-2. Nutrients 2020;12(5):1359. Doi: 10.3390/nu12051359.

23. Rastogi A, Bhansali A, Khare N, et al. Short term, high-dose vitamin $D$ supplementation for COVID-19 disease: a randomised, placebo-controlled, study (SHADE study). Postgrad Med J 2020: postgradmedj-2020-139065. Doi: 10.1136/postgradmedj-2020-139065. Epub ahead of print.

24. Balla M, Merugu GP, Konala VM, et al. Back to basics: review on vitamin $D$ and respiratory viral infections including COVID-19. J Community Hosp Intern
Med Perspect 2020 29;10(6):529-36. Doi: 10.1080/20009666.2020.1811074.

25. Jovic TH, Ali SR, Ibrahim N, Jessop ZM, Tarassoli SP, Dobbs TD, Holford P, Thornton CA Whitaker IS. Could Vitamins Help in the Fight Against COVID-19? Nutrients 2020; 12(9):2550. Doi: 10.3390/ nu12092550.

26. Maghbooli Z, Sahraian MA, Ebrahimi M, et al. Vitamin D sufficiency, a serum 25-hydroxyvitamin $D$ at least $30 \mathrm{ng} / \mathrm{mL}$ reduced risk for adverse clinical outcomes in patients with COVID-19 infection. PLoS One 2020;15(9):e0239799. Doi: 10.1371/journal.pone.0239799.

27. Arboleda JF, Urcuqui-Inchima S. Vitamin D supplementation: A potential approach for Coronavirus/COVID-19 therapeutics? Front Immunol 2020; 11:1523. Doi: 10.3389/fimmu.2020.01523.

28. Panfili FM, Roversi M, D'Argenio P, Rossi P, Cappa M, Fintini D. Possible role of vitamin D in Covid-19 infection in pediatric population.J Endocrinol Invest. 2020:1-9. Doi: 10.1007/s40618-020-01327-0. Epub ahead of print.

29. Marcinowska-Suchowierska E, Kupisz-Urbańska M, Łukaszkiewicz J, Płudowski $P$, Jones $G$. Vitamin D toxicity-A clinical perspective. Front Endocrinol (Lausanne).2018; 9:550. Doi: 10.3389/fendo.2018.00550.

30. MacLaughlin, JA, HolicK, MF. Aging decreases the capacity of human skin to produce vitamin D3. J Clin Invest $1985 ; 76,1536-8$. 